\title{
'Kester' Almond: A Pollenizer for the Late 'Nonpareil' Bloom with High Yield and Kernel Quality
}

\author{
Thomas Gradziel and Bruce Lampinen \\ Department of Plant Sciences, One Shields Avenue, University of California, \\ Davis, CA 95616
}

Additional index words. pollenizer, breeding, delayed bloom, frost avoidance, trait linkage

\section{Origin}

'Kester' is a new almond [Prunus dulcis Miller (D.A. Webb)] cultivar from the breeding program of the University of California at Davis, CA. 'Kester' is cross-compatible and shows good overlap with the later bloom of the dominant California cultivar Nonpareil, and is being released as a pollenizer for 'Nonpareil'. 'Kester' kernels have a similar appearance to 'Nonpareil', but have a darker seedcoat. Trees have an upright spreading and open architecture that produce high yields with tolerance to major pests and diseases.

The 'Kester' almond originated from a cross between 'Tardy Nonpareil' as seed parent and the early-blooming 'Arbuckle'. 'Tardy Nonpareil' is a bud sport of 'Nonpareil', which has a bloom date of $\approx 7$ to $10 \mathrm{~d}$ later (Kester, 1965). This heritable source of delayed bloom is desirable for spring frost avoidance (Dicenta et al., 2017), but has been associated with reduced productivity (Grasselly, 1978). 'Kester', evaluated as selection UCD2-19E, was initially chosen for regional testing as a late-blooming pollenizer for 'Nonpareil' based on its desirable later flowering time, high productivity, and good kernel quality. Most California almond cultivars, including Nonpareil and Kester, are selfincompatible and so self-sterile, requiring cross-compatible pollenizer cultivars for nut set. As a result of its productivity and desirable market quality, 'Nonpareil' currently comprises more than $40 \%$ of the 162,000 ha of commercial production in California (Almond Board of California, 2018). The remaining cultivars are mostly pollenizers for 'Nonpareil', with most blooming with or just before 'Nonpareil'. Although 'Nonpareil' shows good tolerance to frost damage, most pollenizers, which typically bloom in mid February in California, are moderately to highly vulnerable to cold injury, including frost damage (Connell et al., 2018). Climate change is also

Received for publication 23 July 2019. Accepted for publication 23 July 2019 .

We acknowledge the support and valuable contributions from the Almond Board of California as well as from Mario Viveros, Farm Advisor Emeritus, Kern County, CA.

T.G. is the corresponding author. E-mail: tmgradziel @ucdavis.edu. increasing the probability of serious frost damage in production regions previously free from this threat (Dicenta et al., 2017).

Flowering time in almond is determined by the accumulation of sufficient chilling units to overcome flower bud dormancy, followed by the accumulation of sufficient heat units for bud development to flowering (Tabuenca et al., 1972). The 'Tardy Nonpareil' later flowering mutation is desirable because it appears to increase the heat units required for bud development to flowering, but does not affect the chill unit requirement, and because breaking its association with reduced productivity has been shown to be possible (Grasselly and Olivier, 1985). After more than 10 years of promising performance in regional grower test plots in the Sacramento and San Joaquin Valleys, 'Kester' was included in the 2004 Replicated Almond Variety Trial planted in McFarland, CA, with performance evaluated from 2005 to 2012.

\section{Description}

The 'Kester' tree is vigorous and upright to spreading. Production occurs on a combination of spurs and terminal shoots (Fig. 1), and is similar to or slightly smaller than 'Nonpareil' in final tree size. This growth habit confers high productivity with an open tree architecture that allows improved light penetration and air circulation to the canopy interior and so reduces blossom, foliar and fruit disease (Gradziel and Lampinen, 2013). Kernels are similar to 'Nonpareil', with an ovate shape and an oblique base (Fig. 1). The incidence of undesirable kernel types, including double kernels and kernels with multiple embryos is consistently low, similar to 'Nonpareil'. The development of creases or folding of the kernel seedcoat, which is undesirable in the fresh and blanched kernel markets, is also very low. Nuts are well sealed at maturity, providing a high kernel-to-nut crack-out ratio as well as protection from important pests and diseases (Fig. 1). Flowers are large and showy, and are white at full bloom although slightly pink at the bud stage (Fig. 1). Field trials have shown 'Kester' to be fully cross-compatible with 'Nonpareil' and its early-bloom pollenizers. Molecular studies have shown one Sallele in common with 'Nonpareil', whereas the S-allele from the 'Arbuckle' parent appears to be novel and thus potentially cross- compatible with all currently documented commercial incompatibility groups. The name 'Kester' was chosen to acknowledge the extensive contributions to almond knowledge by Professor Dale Kester during his career in the Department of Pomology at the University of California at Davis.

\section{Performance}

'Kester', 'Nonpareil', standard California pollenizers, and 'Marcona' from Spain were evaluated in a replicated grower trial in the major almond-producing region of the southern San Joaquin Valley. Trees were planted in 2004 on Hansen rootstocks in Kern County near McFarland, CA. Soils consisted of McFarland loam and Wasco sandy loam, which are both class I soils. The irrigation system was a double-line drip. A standard tree spacing of $6.1 \mathrm{~m}$ between tree rows and $5.5 \mathrm{~m}$ between trees was used. Pollenizers alternated with 'Nonpareil' rows throughout the orchard, with all trees grown under standard commercial practices. Data were collected from 2005 to 2012 for bloom and harvest time, nut yield and quality, and disease and insect damage. A number of smaller grower plantings at additional Sacramento and San Joaquin Valley sites were also used to verify Kern County findings.

The combination of good overlap with later 'Nonpareil' bloom (Fig. 2), open tree architecture, high flower density (Fig. 1), and crosscompatibility with 'Nonpareil' and its traditional pollenizers resulted in consistently high productivity over the 8 years of evaluation (Table 1). The thin "paper shell" of 'Kester' (Fig. 1) conferred a high crack-out ratio of 0.69 , whereas a good shell seal limited damage by navel orangeworm (Amyelois transitella Walker) to less than the $6 \%$ threshold in all test years. Nuts and kernels of 'Kester' were also similar to 'Nonpareil', but with a darker and more furrowed seedcoat (Fig. 1). Harvest of 'Kester' was just after 'Nonpareil' (Fig. 2), which allowed more efficient use of harvesting equipment. The 'Kester' trees showed low to moderate susceptibility to scab (Fusicladium carpophilum; syn. Cladosporium carpophilum), Alternaria leafspot (Alternaria spp.), and almond hull rot (Rhizopus spp. and Monilinia spp.) (Table 1). 'Kester' shows a desirable combination of high productivity and late flowering.

\section{Availability}

'Kester' is protected by U.S. Plant Patent PP27367, and licenses can be obtained from the University of California Technology Transfer Services, 1850 Research Park Drive, Suite 100, Davis, CA 95618-6134. Propagation material is distributed as a registered virus-tested source through the Foundation Plant Service (FPS), University of California, 1 Shields Avenue, Davis, CA 95616.

\section{Literature Cited}

Almond Board of California. 2018. Almond almanac. Almond Board of California, Modesto, CA. 


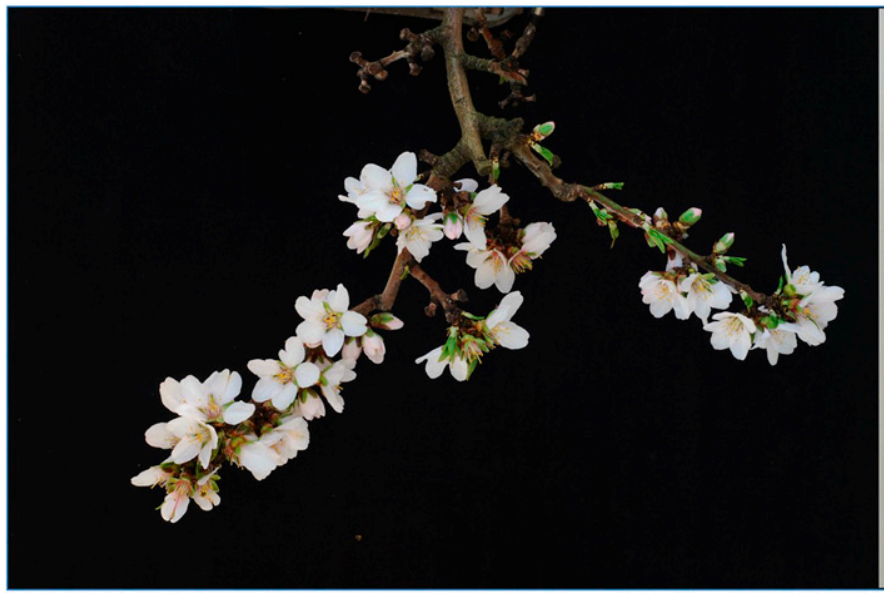

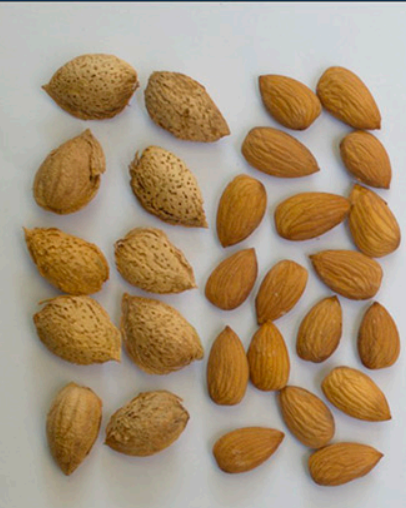

Nonpareil almond

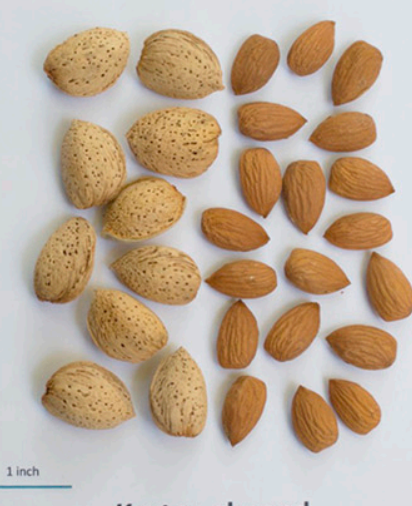

Kester almond

Fig. 1. Flowering branch of 'Kester' showing dense flower and spur production (left). Appearance of in-shell nuts and kernels of 'Kester' compared with 'Nonpareil' (right).

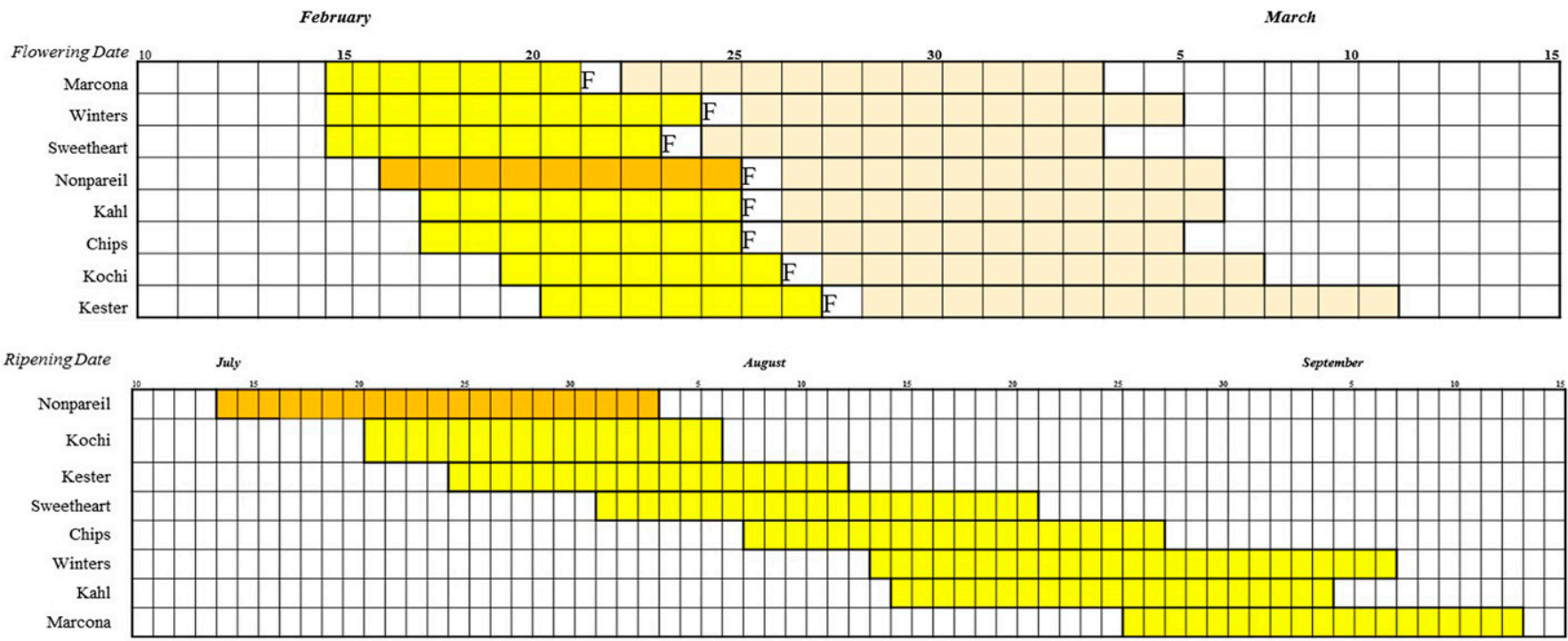

Fig. 2. Average (2006-12) bloom and hull split dates for the Kern trial. Bar chart plots onset of bloom from anthesis to $100 \%$ petal fall. "F" indicates full bloom (top). Hull-split progression from date of initial splitting to greater than $90 \%$ total crop split (bottom).

Table 1. Yield data of mature trees (average of 2010-12) and relative disease susceptibility (2014) of 'Kester' almond compared with 'Nonpareil', 'Marcona', and five other pollenizer cultivars in a replicated trial in Kern County, CA. Cumulative kernel yield is for years 2006-12.

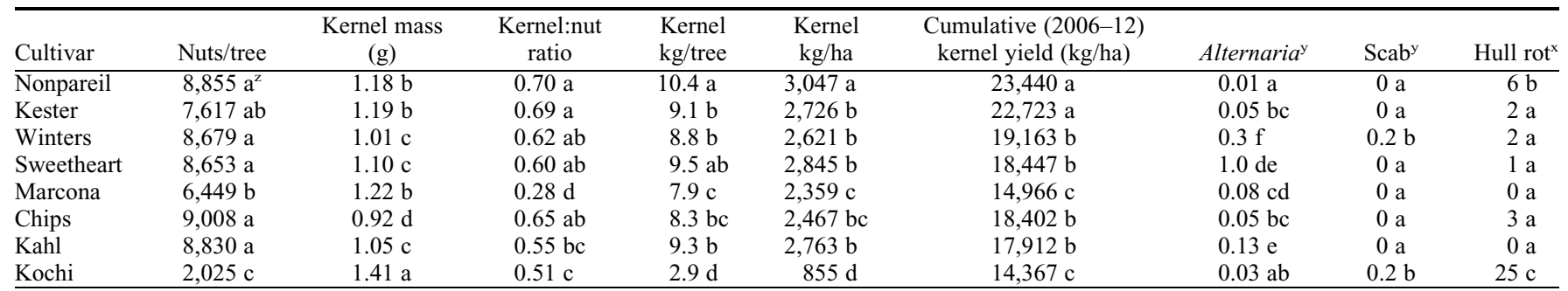

${ }^{\mathrm{z}}$ Mean separation performed within each column by Duncan's multiple range test at $P=0.05$.

${ }^{\mathrm{y}}$ Proportion infected in 100 sampled leaves.

${ }^{\mathrm{x}}$ Strikes per scaffold.

Connell, J.H., T.M. Gradziel, B. Lampinen, W.C. Micke, and P.S. Verdegaal. 2018. Bloom timing of almond cultivars in California. Acta Hort. 1219:25-30.

Dicenta, F., R. Sánchez-Pérez, I. Batlle, and P. Martínez-Gómez. 2017. Late-blooming cultivar development. In: Socias I Company and T. Gradziel (eds.). Almonds: Botany, production and uses. CABI Press, Boston, MA.
Gradziel, T.M. and B.D. Lampinen. 2013. Defining the limits of almond productivity to facilitate marker assisted selection and orchard management. Acta Hort. 912:33-39.

Grasselly, C. 1978. Observations sur l'utilisation d'un mutant d'amandier à floraison tardive dans un programme d'hybridation. Ann. Amelior. Plant. 28:685-695.
Grasselly, C. and G. Olivier. 1985. Avancement du programme 'tardivité de la floraison' chez l'amandier. Options Méditerranéennes 85:47-54. Kester, D.E. 1965. Inheritance of time of bloom in certain progenies of almond. Proc. Amer. Soc. Hort. Sci. 87:214-221.

Tabuenca, M.C., M. Mut, and J. Herrero. 1972. Influence of temperature on the flowering time of almonds. Ann. Aula Dei. 11:378-395. 